SH 177

$$
\frac{F 8.57}{1908}
$$




$$
\begin{aligned}
& 1177 \\
& 8.57 \\
& 908
\end{aligned}
$$




\title{
TREATMENT OF FUNGUS ON FISHES IN CAPTIVITY
}

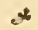

\author{
By L. B. Spencer
}

Department of Zoology and Nature Study, New York Aquarium, New York City

*

Paper presented before the Fourth International Fishery Congress held at Washington, U. S. A., September 22 to 26, 1908

BULLETIN OF THE BUREAU OF FISHERIES : : : : : : VOL XXVIII, P. 929-932

Document No. 691 : : : : : : : : : : : : : : : : : : : : $:$ lssued April, 1910 



\title{
TREATMENT OF FUNGUS ON FISHES IN CAPTIVITY.
}

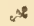 \\ By L. B. SPENCER, \\ Department of Zoology and Nature Study, New York Aquarium, New York City.
}

$*$

A large specimen of brook trout (Salvelinus fontinalis), which was caught with a hook in Sunapee Lake, New Hampshire, was received at the New York Aquarium in the spring of 1896 . The trout had a wound on the head. A few days after being placed in an exhibition tank fungus appeared on the wound. The writer treated the disease by applying salt water from the bay, which is pumped into the aquarium. A hose was used, the end being kept near the head of the trout, so that the stream of salt water reached the wound. This operation was repeated until the fungus disappeared. The wound healed and the fungus did not again appear.

The use of salt water has been continued in the treatment of the fishes. If the water in the bay is not of sufficient saltness to cure fungus, I use enough rock salt to increase the specific gravity to near $\mathrm{I} .028$, which is about the specific gravity of ocean water. Most of our fresh-water fishes will endure this treatment for a time, but it is necessary to keep watch on some species, or they may die if the salt water is used too long.

The usual method employed is to draw the fresh water out of the tank to about 10 or 12 inches in depth, or perhaps less if the fishes are not frightened, stopping the inflow of fresh water at the time. The tank is then filled with salt water. By this method the fishes rarely, if ever, appear to suffer any inconvenience, as the change from fresh to salt water is gradual. When necessary to use rock salt, this is put into the tank before running in the salt water, as the current aids in dissolving it. The water need not be kept in circulation in the large exhibition tanks during the treatment unless one has plenty of salt water to waste; the stream may be cut off for a time, but it is necessary to keep watch on the fishes; as soon as any uneasiness is shown the fresh water should be turned on. It is often necessary to repeat this treatment each day in order to effect a cure.

In the year I 907 and the winter and early spring of 1908 the Croton water was in sucli condition that fungus was inore prevalent, gave more trouble, was 
more difficult to cure, and was fatal in more cases than at any time in the history of the aquarium. Salt-water treatment did not cure as before, and the use of hydrogen dioxide was commenced. If a fish has only two or three diseased spots, it may be taken out of the tank with a net and the dioxide applied with a sponge. When the fungus is distributed over a considerable portion of the body, the fish is immersed in a solution of one part hydrogen dioxide to three or four parts of water. The length of time fishes will endure the treatment varies much with different species. It is necessary to watch them closely or some will be injured or killed.

Fungus has been killed on hundreds of fishes, of many species, in the New York Aquarium, by the application of hydrogen dioxide, and the fishes have been kept on exhibition for weeks, when they would have died in a few days without the treatment. Treatment for fungus should commence as soon as it appears; if not, it soon eats into the body and weakens the fish, making the cure more doubtful.

After treatment it is most necessary to take precautions against a recurrence of the fungus. In my experience, in many cases it is not difficult to kill fungus on fishes, but when this is done the affected place is left a sore, and the fish is more or less weakened by the disease and treatment. Therefore, when put back into the tank in the same water from which the disease was contracted, the fungus soon appears on the places formerly affected. Each recurrence reduces the strength of the fish and in many cases death occurs in time. I believe that if after treatment the fish could be put into new water practically free from fungus the sores would heal and the disease would not reappear. A human being contracts pneumonia and recovers, but is not exempt from contracting the disease again; in fact, under the same conditions, he may be more liable to a second attack.

In March, 1908, when fungus disease was so prevalent in the aquarium, there were two tanks of fishes, one of rock bass (Ambloplites rupestris) and the other spotted or channel catfish (Ictalurus punctatus), both of which species were attacked. Salt water was used, but without any beneficial effect. Hydrogen dioxide solution was used until the fishes were entirely cured. At the present time, September 10, 1908, every specimen of both species is in fine condition.

Fishes in house aquariums can be treated for fungus by taking the diseased specimen out of the aquarium and immersing it in prepared salt water, or in a solution of hydrogen dioxide. A small quantity of either preparation will be sufficient. If kept for some time, the dioxide will lose strength and become less effective. 


$$
\frac{. F 8 S 7}{1908}
$$


Hollinger Corp.

pH 8.5 